\title{
Quantitative Risk assessment of product disulfide bond reduction in a recombinant protein manufacturing
}

Yi Qing cui ${ }^{1}$, rujie meng ${ }^{1}$, and yutong $\operatorname{Li}^{1}$

${ }^{1} \mathrm{WuXi}$ Biologicals

June 24, 2021

\begin{abstract}
Disulfide bond reduction occurred now and then during a recombinant protein manufacturing. Their reduction often led in the loss of batches. Various prevention measures were developed. Their implementation in a manufacturing inevitably increases its operation complexity and even might impact its product qualities and process performances. It is highly desirable to apply a reduction measure only if necessary and to apply no strong measure if a moderate one works. The reduction occurrence is determined both by the reduction sensitivity of a recombinant molecule and by the reduction power of harvested cell culture fluids. The reduction power of harvested cell culture fluids varies largely and depends on cells, lysis level, growth stage, and culture conditions. The method of the quantitative risk assessment of disulfide bond reduction was reported here. The quantitative assessment is realized by comparing the reduction sensitivity of a recombinant molecule with the reduction power of its harvested cell culture fluid.
\end{abstract}

\section{Hosted file}

Main Text for Quantitative risk assessment of biopharmaceutical disulfide bond reduction 2021-06-03.doc available at https://authorea.com/users/421778/articles/527659-quantitative-risk-assessmentof-product-disulfide-bond-reduction-in-a-recombinant-protein-manufacturing

\section{Hosted file}

Figures for Quantitative risk assessment of biopharmaceutical disulfide bond reduction 2021-05-16.docx available at https://authorea.com/users/421778/articles/527659-quantitative-risk-assessmentof-product-disulfide-bond-reduction-in-a-recombinant-protein-manufacturing 